\title{
STUDYING THE DYNAMICS OF ELECTRIC CURRENTS AND POLAR CAPS IN IONOSPHERES OF TWO HEMISPHERES DURING THE AUGUST 17, 2001 GEOMAGNETIC STORM
}

\author{
S.B. Lunyushkin \\ Institute of Solar-Terrestrial Physics SB RAS, \\ Irkutsk, Russia,lunyushkin@iszf.irk.ru \\ V.V. Mishin \\ Institute of Solar-Terrestrial Physics SB RAS, \\ Irkutsk,Russia,vladm@isz..irk.ru \\ Yu.A. Karavaev \\ Institute of Solar-Terrestrial Physics SB RAS, \\ Irkutsk, Russia,ykar@iszf.irk.ru
}

\author{
Yu.V. Penskikh \\ Institute of Solar-Terrestrial Physics SB RAS, \\ Irkutsk, Russia,penskikh@iszf.irk.ru \\ V.E. Kapustin \\ Institute of Solar-Terrestrial Physics SB RAS, \\ Irkutsk, Russia,kapustin@isz.irk.ru
}

\begin{abstract}
The magnetogram inversion technique (MIT), developed at ISTP SB RAS more than forty years ago, has been used until recently only in the Northern Hemisphere. In recent years, MIT has been improved and extended to make instantaneous calculations of 2D distributions of electric fields, horizontal and field-aligned currents in two polar ionospheres. The calculations were carried out based on one-minute ground-based geomagnetic measurements from the worldwide network of stations in both hemispheres (SuperMAG). In this paper, this extended technique is used in the approximation of uniform ionospheric conductance and is applied for the first time to calculations of equivalent and field-aligned currents in two hemispheres through the example of the August 17, 2001 geomagnetic storm. We have obtained the main and essential result: the advanced MIT-ISTP can calculate large-scale distributions of ionospheric convection and FACs in the Northern (N) and Southern (S) polar ionospheres with a high degree of expected hemispheric similarity between these distributions. Using the said event as an example, we have established that the equivalent and field-aligned currents obtained with the advanced technique exhibit the expected dynamics of auroral electrojets and polar caps in two hemispheres. Hall current intensities in polar caps and auroral electrojets, calculated from the equivalent current function, change fairly synchronously in the $\mathrm{N}$ and $\mathrm{S}$ hemispheres throughout the magnetic storm. Both (westward and
\end{abstract}

eastward) electrojets of the $\mathrm{N}$ hemisphere are markedly more intense than respective electrojets of the $\mathrm{S}$ hemisphere, and the Hall current in the north polar cap is almost twice as intense as that in the south one. This interhemispheric asymmetry is likely to be due to seasonal conductance variations, which is implicitly contained in the current function. From FAC distributions we determine auroral oval boundaries and calculate magnetic fluxes through the polar caps in the $\mathrm{N}$ and $\mathrm{S}$ hemispheres. These magnetic fluxes coincide with an accuracy of about $5 \%$ and change almost synchronously during the magnetic storm. In the $\mathrm{N}$ hemisphere, the magnetic flux in the dawn polar cap is more intense that that in the dusk one, and vice versa in the $\mathrm{S}$ hemisphere. These asymmetries (dawn-dusk and interhemispheric) in the polar caps are consistent with the theory of reconnection for IMF $B_{\mathrm{y}}>0$ and with satellite images of auroral ovals; both of these asymmetries decrease during the substorm expansion phase.

Keywords: current function, ionospheric convection, polar cap, auroral electrojets, field-aligned currents, magnetic storms and substorms, dawn-dusk asymmetry, interhemispheric asymmetry.

\section{INTRODUCTION}

There are two hypotheses (models) about the formation of Earth's magnetosphere and their associated mechanisms of mass and energy transfer from the solar wind (SW) to the magnetosphere-ionosphere system. The first one - quasi-viscous interaction model [Axford, Hines, 1961] — is a closed model of the magnetosphere whose boundary (magnetopause) is approximated by a tangential MHD discontinuity. Due to lack of velocity and magnetic field components normal to the magnetopause, the direct mass and energy transfer through it is impossible, but the energy can be transported by magnetosonic waves [Axford, 1964; Leo- novich et al., 2003]. Furthermore, owing to the development of the Kelvin-Helmholtz instability, the flow around the magnetosphere becomes turbulent, diffuse widening of the boundary occurs, and the observed boundary layer is formed [Mishin, 2005]. Both of the mechanisms of energy and mass transfer through the tangential discontinuity work in the closed model of the magnetosphere. Their effectiveness is negligible on the dayside, but it is sufficiently high at the magnetotail boundary (in the region of its supersonic flow), where the total contribution of these two mechanisms to the magnetosphere energy may exceed $20 \%$ (refer also to [Heikkila, 2011]). The second model is "open" [Dungey, 1961] in which the magnetopause in the region of 
IMF reconnection with the geomagnetic field is approximated by the rotational MHD discontinuity, the efficiency of Alfvén wave, mass, and energy transfer through which is several times higher than that in the quasi-viscous mechanism [Lee, Roederer, 1982]. Numerous studies have found that in most cases the development of a magnetospheric substorm is directly related to the appearance of the southward IMF component $B_{z}$ near the frontal part of the magnetosphere, which is qualitatively well described by the open model [Akasofu, 1977; Koskinen, 2011].

The efficiency of the SW-magnetosphere interaction depends not only on $B_{z}$ but also on the azimuthal component $B_{y}$, IMF sector structure, as well as on the SW density and velocity. The development of geomagnetic and auroral activity is due to variations in electric fields and currents in the magnetosphere-ionosphere system, which occur asymmetrically both in the dawn-dusk (east-west) direction and between the $\mathrm{N}$ and $\mathrm{S}$ hemispheres. There are both internal and external causes of these asymmetries. The inclination of the geomagnetic dipole axis (the annually and daily variable angle between the Earth-Sun line and the plane of the geomagnetic equator) is one of the major internal causes responsible for the different seasonal and daily variations in the solar-radiation driven ionospheric conductance in two hemispheres. The inequality between day-night illuminances creates a sunward conductance gradient different in each hemisphere, which causes plasma convection to increase in the dawn sector of the polar cap [Leontyev, Lyatsky, 1974; Mishin et al., 1981]. The main external causes of the dawn-dusk and interhemispheric asymmetries are changes in the IMF sector structure, polar angle, and $B_{y}$ component [Haaland et al., 2017].

According to the theory [Cowley, 1981; Cowley, Lockwood, 1992], $B_{y}$ determines the location of the dayside throat (input) of the ionospheric convection relative to the noon-midnight meridian and also causes the polar cap (PC) to shift along the dawn-dusk meridian in a direction opposite to the IMF vector $\mathbf{B}_{y}$ (refer also to [Mishin et al., 1992]). In the inner magnetosphere, $B_{y}$ is superimposed on the geomagnetic field, which brings about the formation of the asymmetric pattern of the magnetospheric convection in both magnetotail lobes [Cowley, 1981; Tenfjord et al., 2015]. The asymmetric loading of the open magnetic flux following the daytime reconnection in the magnetotail lobes produces $B_{y}$ in them within 5-10 min [Tenfjord et al., 2017]. This corresponds to the estimate of the characteristic time of the response of the magnetospheric-ionospheric convection to IMF variations [Ridley et al., 1998]. From optical satellite observations it has been found that the sign of $B_{y}$ determines the shift of the auroral oval to the dawn or dusk side oppositely in two hemispheres [Haaland et al., 2017; Østgaard et al., 2018].

The main laws of the influence of the polar angle, formed by $B_{y}$ and $B_{z}$, on the distribution of the electric potential (convection) and field-aligned currents (FACs) in the polar ionosphere are contained in the known models obtained from statistical processing of meas- urements of electric and magnetic fields along numerous satellite passages [Weimer, 2001, 2005; Papitashvili, Rich, 2002]. A great advance in the study of the ionospheric convection structure and dynamics is associated with the implementation of the SuperDARN project [Pettigrew et al., 2010]. All these global averaged models do not, however, reflect the instantaneous picture of ionospheric convection and FACs as well as their spatiotemporal dynamics during magnetospheric substorms having a characteristic time scale of $\sim 10 \mathrm{~min}$ to $1 \mathrm{hr}$. In the last decade, this drawback has largely been overcome due to the beginning of the multisatellite project AMPERE [Coxon et al., 2018]. Simultaneous continuous magnetic measurements along trajectories of 66 satellites, distributed in six orbital planes, are automatically processed using a specially developed method. Results of these calculations are 10-min averaged large-scale distributions of FAC density, which corresponds to the time shift between adjacent satellites following one another in one plane. It is obvious that on the thus obtained maps FAC mesoscale structures during fast processes $(<10 \mathrm{~min})$, typical of magnetospheric substorms especially in the expansion phase, are strongly smoothed and attenuated.

The Magnetogram Inversion Technique (MIT, hereinafter without "ISTP") does not have this drawback and can calculate 2D distributions of current function, electric potential, horizontal and field-aligned currents in the polar ionosphere with a time step of $1 \mathrm{~min}$ from existing databases of continuous geomagnetic measurements made at the worldwide network of ground magnetometers, the total number of which in two hemispheres is now more than two hundreds. Note particularly that owing to very non-uniform distribution of ground stations MIT is inferior to AMPERE with sufficiently uniform distribution of satellites at a height of $780 \mathrm{~km}$. Nevertheless, MIT has obvious advantages both in the number of ground magnetometers (200) and in its low cost as compared to the expensive satellite project AMPERE. The method for potential analysis of the geomagnetic field and calculation of the current equivalent function is described in detail in the classic monograph by Chapman and Bartels [1940]. At ISTP SB RAS, bases for MIT were developed over forty years ago [Mishin, Bazarzhapov, 1966; Mishin, Popov, 1969; Matveev, Shpynev, 1975; Bazarzhapov et al., 1979; Mishin, 1990], and similar magnetogram inversion variants were almost simultaneously worked out at IZMIRAN [Levitin et al., 1982; Papitashvili et al., 1994] and abroad (KRM) [Kamide, Matsushita, 1979; Kamide, Baumjohann, 1993]. In this paper, we use the recently updated MIT providing 2D distributions of specified electrodynamic parameters of the ionosphere in two hemispheres at a time.

Despite the fairly large number of empirical data available in the literature, statistical and theoretical models, the main laws, physical processes, and mechanisms of interaction of SW and IMF with the magnetosphere, as well as their effects in two hemispheres are not fully understood. Nowadays, one of the important areas of research in Earth's magnetosphere physics is 
the study of theoretically expected dawn-dusk and noon-night asymmetries, as well as asymmetries between the Northern and Southern hemispheres [Haaland et al., 2017]. The asymmetries are investigated in the magnetospheric-ionospheric convection, ionospheric and field-aligned currents, auroras, dynamics of boundaries, configurations of auroral ovals and polar caps, as well as in other electrodynamic and topological parameters of the magnetosphere-ionosphere system. MIT can contribute to the studies in this area.

Our work is methodical, and its main purpose is the first testing of the updated MIT for calculating 2D distributions of convection, horizontal and field-aligned currents simultaneously in two hemispheres in the approximation of uniform conductances of the northern and southern polar ionospheres. The main criterion for applicability of the method in the Southern Hemisphere is that large-scale systems of ionospheric convection and FACs should be similar to those in the Northern Hemisphere. To examine the dynamics of the main ionospheric Hall currents and polar caps in two hemispheres for the selected magnetic storm as an example and to compare the results with the facts generally accepted in the literature is the second objective of this work also aimed at confirming the applicability of MIT for the Southern Hemisphere.

Section 1 describes the databases of ground and satellite observations and methods of their processing and analysis. Section 2 compares ionospheric convection and FAC maps, as well as Hall currents and polar caps in ionospheres of two hemispheres. The main results and conclusions are presented in Conclusion.

\section{DATABASE AND METHODS}

Two-dimensional distributions of the equivalent current function, electric potential, horizontal and fieldaligned currents, and other parameters of the polar ionosphere were calculated based on MIT until recently only for the Northern Hemisphere and using input geomagnetic data only from a part of the worldwide network of ground stations, located to the north of the equator.

In recent years, an important advance in the MIT software package was the extension of the method for spherical harmonic analysis (the first main MIT block) into both hemispheres. This was due to the implementation of the large project SuperMAG [Gjerloev, 2012]. The website [http://supermag.jhuapl.edu] provides free access to the database of geomagnetic observations from the worldwide network of over 200 ground magnetic stations (e.g., in the late 2017, their total number was 217,180 of them in the Northern Hemisphere and 37 in the Southern Hemisphere). The database was verified using the common method.

In this paper, we first test the extended MIT for calculations of equivalent and field-aligned current systems for the selected magnetic storm of August 17, 2001 (Figure 1), using one-minute data on ground geomagnetic variations from all stations of the worldwide network in both hemispheres, available in the SuperMag database. The total number of stations operating during the August 17, 2001 event was 179, including 149 in the $\mathrm{N}$ hemisphere and 30 in the $\mathrm{S}$ hemisphere. While stations in the $\mathrm{S}$ hemisphere were five times fewer than in the $\mathrm{N}$ hemisphere, the extended MIT allowed us to obtained first expected and interpreted results for the $\mathrm{S}$ hemisphere as well (see Section 2).

An important input MIT parameter is the original dynamic model of polar ionosphere conductance [Mishin et al., 1986; Shirapov et al., 2000], produced by the precipitation of energetic particles. The model is based on three main auroral oval boundaries (Figure 2): polar cap (R0), line of maximum density of auroral electrojets (R1), auroral oval equatorial boundary (R2). The R0 boundary corresponds to the high-latitude boundary of Iijima-Potemra (IP) FAC Region 1 [Iijima, Potemra, 1978]; R2, to the low-latitude boundary of FAC Region 2; and $\mathrm{R} 1$ coincides with the boundary between FAC Regions 1 and 2 . The letter $\mathrm{R}$ in the notations denotes Radius (boundary radius) and not Region (FAC Region). The described method for determining boundaries of the polar cap and auroral oval equatorial boundary was put into common practice of MIT [Mishin et al., 1984, 1986] in view of the results obtained in [Iijima, Potemra, 1978; Coley, 1983]. This method has recently been used to develop a new, updated and automated method for diagnostics of auroral oval boundaries [Kondratyev et al., 2017; Lunyushkin, Penskikh, 2019].

It should be noted here that the large-scale structure of the main areas of IP FACs (and hence their associated auroral oval boundaries) is little sensitive to the choice of ionospheric conductance model. This fundamentally important fact was established already in the first variants of MIT [Mishin et al., 1981] and KRM [Kamide, Richmond, 1982; Kamide, Baumjohann, 1993]. The physical meaning of this fact is that the magnetospheric source of FAC $\left(\Sigma_{\mathrm{P}}\left(\nabla \cdot \mathbf{E}_{\mathrm{m}}\right)\right.$, where $\mathbf{E}_{\mathrm{m}}$ is the electric field in the magnetosphere), is primary, and the ionospheric one (associated with $\nabla \Sigma_{\mathrm{P}}$ and $\nabla \Sigma_{\mathrm{H}}$ ) is secondary [Boström, 1974]. The locations of the R0, R1 and R2 boundaries determined by the above method from FAC distribution maps, obtained for uniform and nonuniform conductances, coincide up to $\pm 1^{\circ}$ in latitude (see Subsection 3.4 and Figure 7 [Lunyushkin, Penskikh, 2019]). The minor influence of the conductances on the large-scale structure of FACs is also confirmed by the results of long-term practice in solving two basic MIT equations [Matveev, Shpynev, 1975; Bazarzhapov et al., 1979]:

$$
\begin{aligned}
& \operatorname{rot}_{r}(\hat{\Sigma} \cdot \nabla U)=-\Delta J \\
& \operatorname{div}_{\perp}(\hat{\Sigma} \cdot \nabla U)=i \sin I,
\end{aligned}
$$

where $\hat{\Sigma}$ is the tensor of integrated ionospheric conductance; $U$ is the electric potential of the ionosphere; $J$ is the equivalent current function; $i$ is the FAC density; $I$ is the magnetic inclination; $\operatorname{div}_{\perp}$ is the $2 \mathrm{D}$ divergence operator; $\operatorname{rot}_{r}$ is the radial rotor component; $\Delta$ is the $2 \mathrm{D}$ Laplace operator.

FACs are found from Equation (2), using the solution of Equation (1) in terms of the potential $U$ for the 

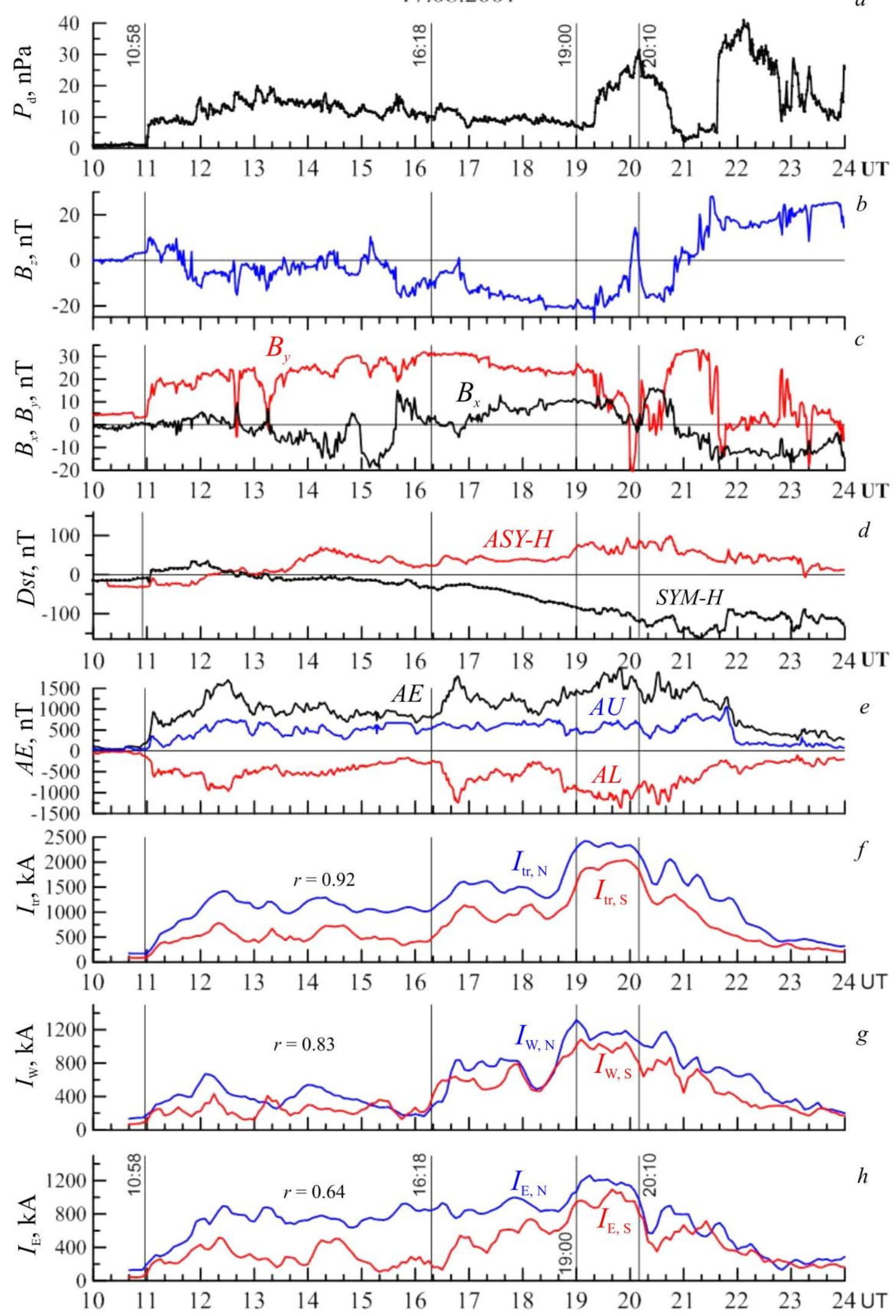

Figure 1. Geophysical conditions during the August 17, 2001 magnetic storm: variations in the solar wind dynamic pressure $P_{\mathrm{d}}(a)$; IMF components $B_{z}(b)$ and $B_{x, y}(c)$; indices of ring current $(d)$ and auroral activity $A E, A L, A U(e)$. Bottom panels show variations in intensities of the main Hall currents in the Northern ( $\mathrm{N}$, blue curves) and Southern (S, red curves) hemispheres: transpolar currents $I_{\mathrm{tr}, \mathrm{N}}, I_{\mathrm{tr}, \mathrm{S}}(f)$; westward $I_{\mathrm{W}, \mathrm{N}}, I_{\mathrm{W}, \mathrm{S}}(g)$ and eastward $I_{\mathrm{E}, \mathrm{N}}, I_{\mathrm{E}, \mathrm{S}}(h)$ electrojets; correlation coefficients $r$ between currents in two hemispheres. Vertical lines indicate the moments of time discussed in the text: SSC (10:58 UT), beginning (16:18 UT) and end (19:00 UT) of optical satellite observations [Østgaard et al., 2018] 
given conductance model $\hat{\Sigma}$. In the above studies [Mishin et al., 1981; Kamide, Richmond, 1982], it was found that in contrast to FAC the distribution of the electric potential $U$ is very sensitive to the choice of the model $\hat{\Sigma}$. The correctness of the solution for Equation (1) in terms of $U$ strongly depends on the spatial correlation between irregularities of the tensor $\hat{\Sigma}$ and the inhomogeneous right-hand side of Equation (1) [Mishin et al., 1981; Reiff, 1984]. The main criterion of the proper solution for $U$ is the solution in the form of a two-vortex ionospheric convection system, which generally should be similar to the two-vortex current function $J$. In the uniform conductance and radial geomagnetic field approximation $I=0$, from (1), (2) it is easy to obtain simpler equations [Kern, 1966; Lunyushkin, Penskikh, 2019]

$$
\begin{aligned}
& J=\mp \Sigma_{\mathrm{H}} U+\text { const } ; \\
& i=-\left(\Sigma_{\mathrm{P}} / \Sigma_{\mathrm{H}}\right) \Delta J,
\end{aligned}
$$

where in (3) the minus sign corresponds to the Northern Hemisphere; and the plus sign, to the Southern Hemisphere; $\Sigma_{\mathrm{P}}$ and $\Sigma_{\mathrm{H}}$ are integral uniform Pedersen and Hall conductances.

In view of the above, we use the $2 \mathrm{D}$ distributions of the equivalent current functions, calculated in the uniform ionospheric conductance approximation simultaneously in two hemispheres, to study the dynamics of the major large-scale ionospheric Hall currents and convection (ionospheric plasma drift):

$$
\begin{aligned}
& \mathbf{j}_{\mathrm{H}}=\nabla \boldsymbol{J} \times \mathbf{n}, \\
& \mathbf{V}=-\frac{1}{\Sigma_{\mathrm{H}} B} \mathbf{j}_{\mathrm{H}},
\end{aligned}
$$

where $\mathbf{V}$ is the drift velocity, $B$ is the geomagnetic field modulus, $\mathbf{n}$ is external normal.

The 2D distributions of FAC density calculated from Formula (4) are used to find auroral oval boundaries in the Northern and Southern hemispheres. The above method of drawing the R0, R1, and R2 boundaries on FAC maps and locations of the main ionospheric Hall currents on maps of $J$ are illustrated in Figures 2, 3.

The most important output parameter of MIT — the magnetic flux $\Psi=\iint_{S} \mathbf{B} \cdot d \mathbf{S}$ through the polar cap $S$ is calculated in the geomagnetic dipole approximation from the formula

$$
\Psi=\frac{\mu_{0} M_{\mathrm{E}}}{4 \pi r} \int_{0}^{2 \pi} \sin ^{2} \theta_{0}(\lambda) d \lambda,
$$

where $\theta_{0}(\lambda)$ is the colatitude of the polar cap boundary R0 (counted from the pole of the geomagnetic dipole) as function of longitude $\lambda=\mathrm{MLT} ; \mu_{0}$ is the magnetic constant; $M_{\mathrm{E}}$ is the magnetic dipole moment of Earth; $r=R_{\mathrm{E}}+h$, where $R_{\mathrm{E}}=6371 \mathrm{~km}, h=115 \mathrm{~km}$.

The parameter $\Psi$ is a measure of the open magnetic flux in magnetotail lobes and is used in MIT [Mishin et al., 1984, 1997, 2014] to estimate the power of the
SW-magnetosphere generator whose operation is ensured by the mechanism of reconnection in the open magnetosphere model, described in Introduction.

Subsection 2.3 presents the first results of the study of the simultaneous dynamics of magnetic fluxes in the north and south polar caps during the August 17, 2001 magnetic storm. The results have been obtained by the extended MIT. This subsection also analyzes results of the dynamics of polar cap boundaries asymmetric to the dawn-dusk direction in two hemispheres and respective magnetic fluxes through the dawn and dusk parts of the polar caps.

The method of determining the PC boundary from the high-latitude boundary of FAC Region 1 gives results up to $\pm 2^{\circ}$ in latitude as compared to direct methods of determining the PC boundary from satellite data on precipitating particles and auroras [Coley, 1983; Mishin et al., 1992, 1997; Milan et al., 2010; Karavaev et al., 2013; Heelis, 2016]. In Subsection 2.3, the PC boundaries identified in two hemispheres by MIT are compared with the photographs of auroral ovals in two hemispheres obtained from IMAGE and Polar satellites for the August 17, 2001 event [Østgaard et al., 2018].

To evaluate geophysical conditions in this event, we have used one-minute data on SW, IMF parameters, and geomagnetic indices [https://omniweb.gsfc.nasa.gov, http://wdc.kugi.kyoto-u.ac.jp/index.html].

\section{CONVECTION, ELECTRIC CURRENTS AND AURORAL OVALS IN TWO HEMISPHERES}

The powerful magnetospheric storm of August 17, 2001 has been investigated in a number of papers [Cattell et al., 2011; Karavaev et al., 2011; Longley et al., 2017; Østgaard et al., 2018]. It featured the following geophysical conditions. Around 11:00 UT, a large coronal mass ejection (CME) approached the dayside magnetopause of Earth. It caused a strong geomagnetic storm accompanied by several substorms with intense auroras in both hemispheres. These auroras were almost simultaneously photographed by cameras of the IMAGE ( $\mathrm{N}$ hemisphere) and Polar (S hemisphere) satellites [Longley et al., 2017; Østgaard et al., 2018]. This storm had extraordinary IMF values: the azimuthal component over a long 9-hour interval 11-20 UT was within $20<B_{y}<30$ nT (see Figure 1. $c$ ); the IMF component $B_{z}$ was southward throughout this interval and also reached extreme values $B_{z}=-20 \mathrm{nT}$ (see Figure 1, b). At 10:58 UT (SSC is the sudden storm commencement), the impact of the SW shock front on the dayside boundary of the magnetosphere with an abrupt rise (almost ten times) in dynamic pressure $P_{\mathrm{d}}$ (see Figure $1, a$ ) caused a sharp compression of the boundary, which occurred with respective amplification of DCF currents at the magnetopause, auroral geomagnetic activity indices $A E, A L$, and $A U$ (see Figure $1, e$ ), and Dst indices of the ring current $S Y M-H$ and $A S Y-H$ (see Figure $1, d$ ). Within 10-24 UT of the magnetic storm, there were several substorm activations, with two substorms standing out in the interval from 16:15 to $20: 10$ UT with expansion phase onsets at 16:18 and 18:40 UT. 

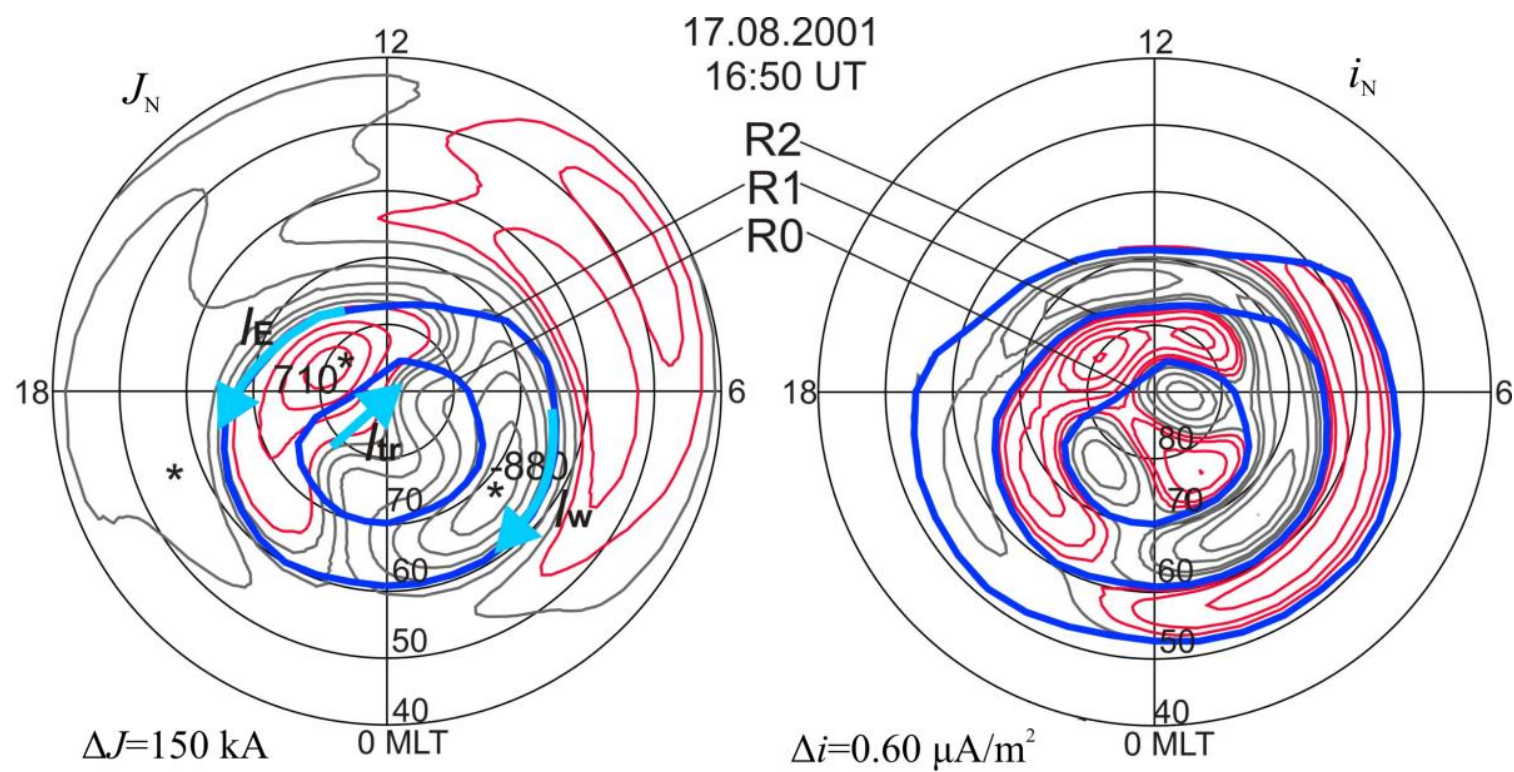

Figure 2. Two-dimensional distributions (geomagnetic latitude - local geomagnetic time) of the equivalent current function $J_{\mathrm{N}}$ and FAC density $i_{\mathrm{N}}$ in the ionosphere of the Northern Hemisphere. Red isolines on the FAC map are downward FACs; black isolines, upward FACs. Thick dark blue lines: R0 is the polar cap boundary; R1 is the line of maximum density of auroral electrojets (boundary between FAC Regions 1 and 2); R2 is the equatorial boundary of FAC Region 2 (auroral oval). Blue arrows indicate the main Hall currents: transpolar current $I_{\mathrm{tr}}$, eastward $I_{\mathrm{E}}$ and westward $I_{\mathrm{W}}$ electrojets
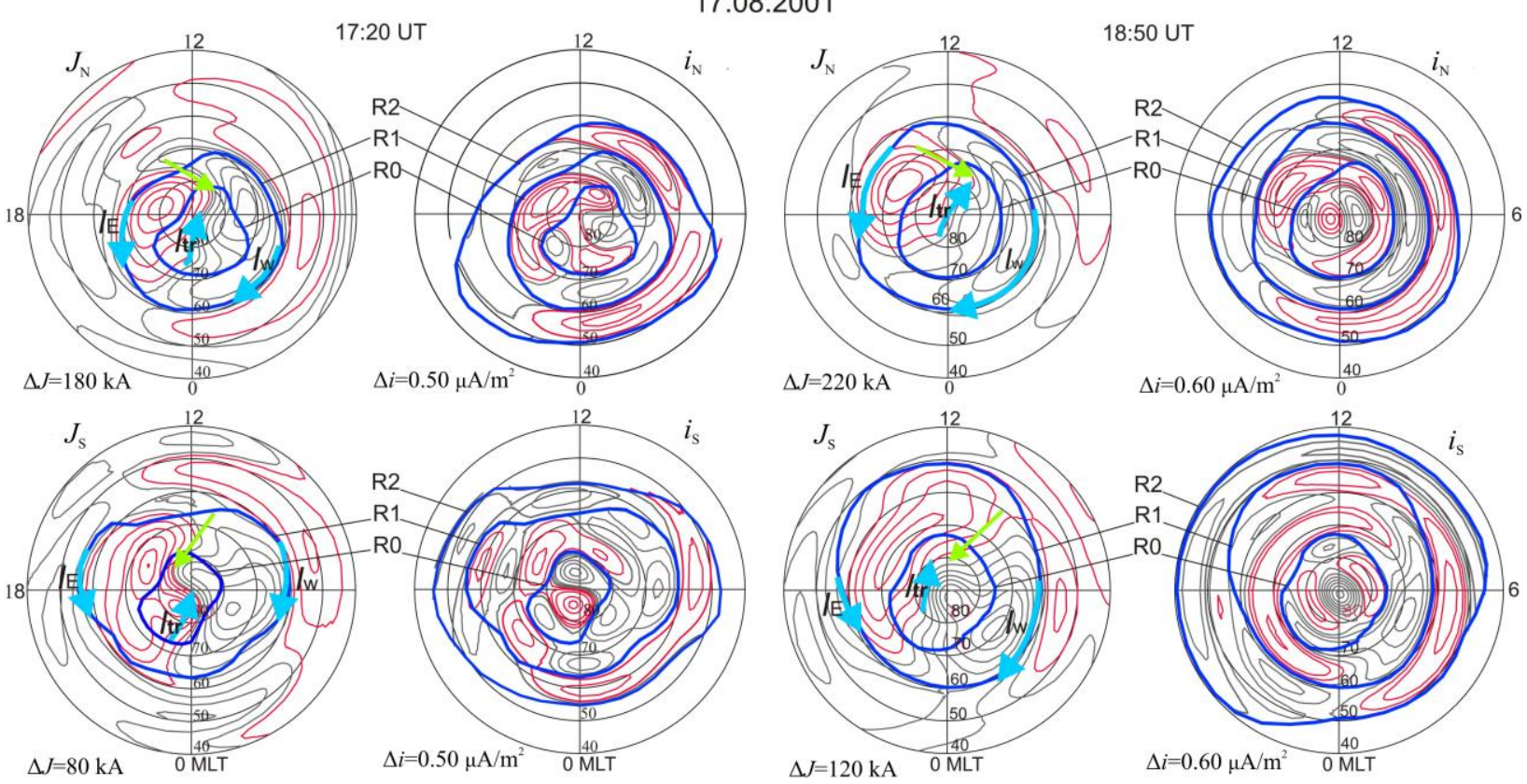

Figure 3 . The top panel shows $2 \mathrm{D}$ distributions of the current function $J_{\mathrm{N}}$ and FAC density $i_{\mathrm{N}}$ in the ionosphere of the $\mathrm{N}$ hemisphere for the growth 17:20 UT and expansion 18:50 UT phases of the August 17, 2001 substorm. The bottom panel (through Earth) demonstrates the corresponding $2 \mathrm{D}$ distributions of $J_{\mathrm{S}}$ and $i_{\mathrm{S}}$ in the $\mathrm{S}$ hemisphere; green arrows indicate locations of dayside throats in two hemispheres and different directions of convection in them for $B_{y}>0$; blue arrows show Hall current; dark blue closed lines are auroral oval boundaries. All notations are the same as in Figure 2

For the entire interval of these substorms there are published images of auroras obtained simultaneously in two hemispheres from the IMAGE and Polar satellites. At 20:10 UT when the SW dynamic pressure was maximum (see Figure 1,a), there was a sharp 20-min northward jump of IMF (see Figure 1, b), which might have caused the expansion phase of the second substorm to continue. This is evident from the increase in the auroral indices (see Figure 1,e).

\subsection{Ionospheric convection and field-aligned currents}

The current function according to (3), (5), and (6) is an analog (with the opposite sign) to the electrostatic potential of the ionosphere, whose isolines correspond to the lines of ionospheric plasma drift (convection). The large-scale magnetospheric-ionospheric convection is the fundamental physical phenomenon in Earth's 
magnetosphere, which continuously exists due to the constantly operating mechanisms of quasi-viscous interaction and magnetic reconnection described in Introduction. These mechanisms in corresponding boundary layers provide continuous operation of two physically different EMF (electromotive force) generators, which create the magnetospheric convection system in the form of two large-scale vortices [Axford, Hines, 1961; Dungey, 1961]. Region 1 FACs transmit electric potentials along highly conducting magnetic field lines from external EMF generator plates to the polar ionosphere, thus forming an analogous (two-vortex) ionospheric convection system [Heikkila, 2011; Milan et al., 2017]. It is obvious that at a low angle of geomagnetic dipole inclination and/or at an IMF polar angle ineffective for reconnection the magnetotail topology should be sufficiently symmetric about the equatorial plane. In such cases, we may expect a strong hemispheric similarity between large-scale distributions of the ionospheric convection and main $\mathrm{FAC}$ regions.

Notice that there is a foreign method AMIE analogous to MIT [Richmond, Kamide, 1988], which in addition to ground geomagnetic data from the worldwide network of stations in both hemispheres utilizes radar and satellite measurements of electric fields and currents in the ionosphere as well as optical data on auroras. This method has been successfully applied to electric potential and FAC calculations in two hemispheres [Lu et al., 1994, 2011; Deng et al., 2009].

Extending MIT for two hemispheres, we were not sure in advance that we could obtain good results for the Southern Hemisphere at once since in the Northern Hemisphere we also constantly suffer a shortage of magnetic stations in the Russian Arctic sector. Nevertheless, the first calculations based on MIT extended for two hemispheres and the SuperMAG database for three isolated substorms (August 27, 2001, July 24, 2003, January 09, 2008) gave the expected results for the Southern Hemisphere, which will soon be published.

In this paper, using MIT for the uniform conductance and SuperMAG database described in Section 1, we calculate 2D distributions of the current function (an analogue of the electric potential) and FAC with a oneminute step in ionospheres of two hemispheres for the selected interval 16-20 UT of the August 17, 2001 magnetic storm.

The comparative analysis of about two hundred maps of equivalent current function distributions in two hemispheres allows us to do a quite reasonable conclusion: the extended MIT enables us to calculate largescale distributions of the ionospheric convection and field-aligned currents simultaneously in two hemispheres, with the $S$ hemisphere maps corresponding to the $N$ hemisphere ones with a high degree of expected similarity.

A typical example confirming this conclusion is given in Figure 3 for two moments (substorm growth and expansion phases) of the selected event. In both the cases, between two hemispheres there is a sufficiently close similarity in the large-scale distributions of equivalent currents (convection) and main FAC Regions 1 and 2.
The maps of current function isolines (as an analogue of convection lines) shown in Figure 3 also confirm the fact that the location of the dayside throat relative to the noon meridian is different in two hemispheres. Green arrows of velocity vectors indicate directions of the throats of convection in the $\mathrm{N}$ and $\mathrm{S}$ hemispheres, which correspond to the IMF sign (or direction) $B_{y}>0$ [Cowley, 1981; Cowley, Lockwood, 1992].

\subsection{Ionospheric Hall currents}

The equivalent Hall current coincides exactly with the actual Hall current in two cases: 1) at the radial geomagnetic field and uniform conductance [Kern, 1966; Fukushima, 1971] or 2) when conductance gradients are perpendicular to the ionospheric plasma convection lines [Laundal et al., 2015]. The only external source of ground geomagnetic field variations in these cases is the equivalent current system consisting of divergence-free Hall currents (5). The radial approximation ignoring the terrestrial magnetic effect of FACs introduces an error $\sim 5-20 \%$ into calculations in $10^{\circ}<\theta<30^{\circ}$ [Fukushima, 1976; Sun et al., 1985]. The condition of perpendicularity of convection lines and conductance gradients is well fulfilled in the sectors of the westward and eastward electrojets flowing azimuthally along the auroral oval, the main conductance gradient in which is latitudinal. In PC $\left(\theta<10^{\circ}\right)$, the geomagnetic field is nearly radial, and conductances are sufficiently uniform on both its dayside and nightside, separated by the terminator determining the main day-night conductance gradient.

Thus, proceeding from the above, we can examine and compare the simultaneous dynamics of the main parameters of equivalent Hall currents in ionospheres of two hemispheres with a sufficient geophysical error (less than $20 \%$ ), considering these currents as real ionospheric Hall currents with the said accuracy.

We have studied the dynamics of three Hall currents (see Figures 2, 3): westward $I_{\mathrm{W}}$ and eastward $I_{\mathrm{E}}$ auroral electrojets, and transpolar current $I_{\text {tr }}$. The intensity of $I_{\text {tr }}$ through PC was determined as a sum of moduli of two main focuses on the current function maps. The intensity of each of the auroral electrojets was estimated by integrating (5) along the meridian passing through the main focus, within the boundaries corresponding to Region 1 and 2 FAC density maxima. In this case, we further checked the equality $I_{\mathrm{tr}}=I_{\mathrm{W}}+I_{\mathrm{E}}$, resulting from the two-vortex convection system.

The described method provided estimates of intensities of Hall currents in the Northern $I_{\mathrm{tr}, \mathrm{N}}, I_{\mathrm{W}, \mathrm{N}}, I_{\mathrm{E}, \mathrm{N}}$, and Southern $I_{\mathrm{tr}, \mathrm{S}}, I_{\mathrm{W}, \mathrm{S}}, I_{\mathrm{E}, \mathrm{S}}$ hemispheres for the entire interval 10-24 UT of the August 17, 2001 magnetic storm. The main results follow from the plots on three bottom panels $(f-h)$ of Figure 1.

1. Variations in intensities of the three Hall currents during the selected magnetic storm occur quite synchronously in both hemispheres, as evidenced by the high correlation coefficients: $r_{\mathrm{tr}}=0.92$ for the transpolar currents $I_{\mathrm{tr}, \mathrm{N}}$ and $I_{\mathrm{tr}, \mathrm{s}}$; for westward and eastward electrojets respectively $r_{\mathrm{W}}=0.83$ and $r_{\mathrm{E}}=0.84$.

2. Intensities of all Hall currents in the Northern Hemisphere during the magnetic storm exceed those of the 
respective Hall currents in the Southern Hemisphere; the Hall current through the polar cap in the Northern Hemisphere is $\sim 1.8$ times stronger than that through the polar cap in the Southern Hemisphere.

Result 1 supports the conclusion drawn in Subsection 2.1; and result 2, the expected interhemispheric asymmetry caused by the difference between seasons: in the $\mathrm{N}$ hemisphere, August 17, 2001 is summer, and in the S hemisphere this day is winter. The conductance produced by solar radiation is therefore higher in the $\mathrm{N}$ hemisphere. While we use the approximation of uniform conductance in both hemispheres, the seasonal effect of wave conductance is implicitly present in the current functions calculated from ground geomagnetic variations. The variations are caused by real ionospheric currents flowing in the ionosphere with the real non-uniform conductance consisting of non-uniform conductances both wave and corpuscular (produced by particle precipitation). If the pattern of precipitation in the symmetric model of substorm is the same, the role of interhemispheric asymmetry in wave conductances becomes primary. Then, in the simplest electric circuit of parallel connection of two loads (ionospheres of two hemispheres) to the common EMF generator (current disruption or reconnection in the near tail) the current intensi- ties will be higher in the load with higher conductance. From Result 2 and Formula (3) it follows that the Hall conductance in the north $\mathrm{PC}$ is $\sim 1.8$ times higher than that in the south PC.

\subsection{Polar cap boundary and magnetic flux}

Using the method described in Section 1, we found the auroral oval boundaries R0, R1, and R2 in both hemispheres for the entire period 10-24 UT of the August 17, 2001 magnetic storm. Then, using the datasets of PC R0 coordinates obtained for each hemisphere, from Formula (7) we calculated the magnetic fluxes through the north $\left(\Psi_{\mathrm{N}}\right)$ and south $\left(\Psi_{\mathrm{S}}\right)$ polar caps. To study the expected (see Introduction) dawn-dusk asymmetry in the dynamics of polar caps of two hemispheres, we also computed magnetic fluxes through dawn and dusk PC parts separated by the noon-midnight meridian: $\Psi_{\mathrm{N} \text {, dawn }}$ and $\Psi_{\mathrm{N} \text {, dusk }}$ in the $\mathrm{N}$ hemisphere; $\Psi_{\mathrm{S} \text {, dawn }}$ and $\Psi_{\text {S, dusk }}$ in the $\mathrm{S}$ hemisphere.

Figure 4 shows variations in these magnetic fluxes in the interval from 16:15 to 19:00 UT for which there are published images of auroras [Østgaard et al., 2018]. Figure $4, c, d$ shows variations in the magnetic fluxes through the north $\left(\Psi_{\mathrm{N}}\right.$, blue curve $)$ and south $\left(\Psi_{\mathrm{S}}\right.$, red

17.08.2001
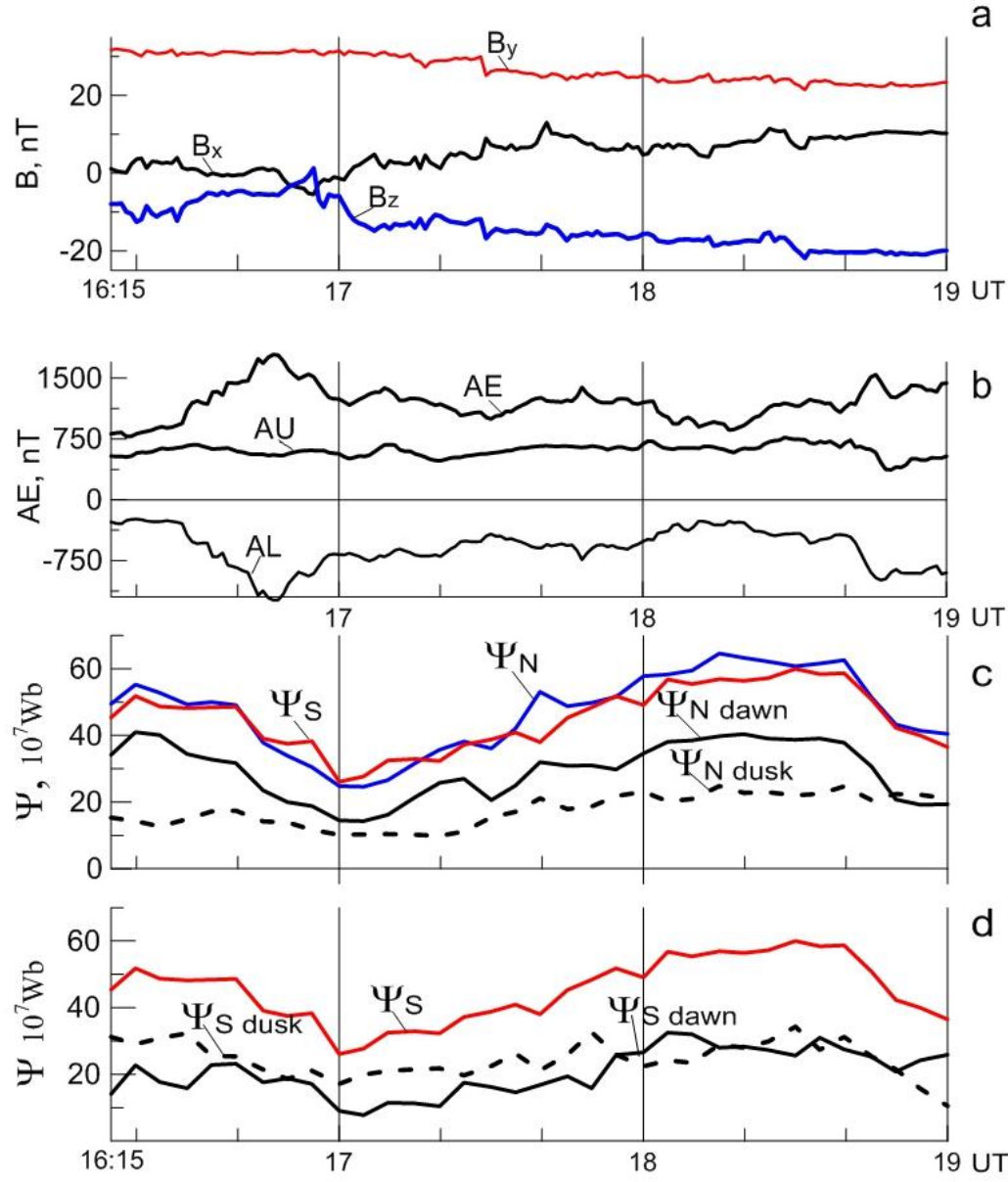

Figure 4. IMF components $(a)$ and auroral indices $(b)$ in the 16-19 UT substorm interval of the August 17, 2001 magnetic storm; variation in the magnetic flux $\Psi_{N}$ (blue line) through the polar cap in the $\mathrm{N}$ hemisphere and magnetic fluxes in the dawn $\left(\Psi_{\mathrm{N}, \text { dawn }}\right.$, thick black line $)$ and dusk $\left(\Psi_{\mathrm{N} \text {, dusk }}\right.$, dashed line) PC parts $(c)$; the same for the $\mathrm{S}$ hemisphere $(d)$ 
curve) PC, as well as variations in magnetic fluxes in the dawn $\left(\Psi_{\mathrm{N} \text {, dawn }}, \Psi_{\mathrm{S} \text {, dawn }}\right.$, thick black line $)$ and dusk $\left(\Psi_{\mathrm{N} \text {, dusk }}\right.$, $\Psi_{\text {s, dusk }}$, dashed black curve) PC parts in two hemispheres. The variations in magnetic fluxes show the expected results.

1. Magnetic fluxes in the polar caps of Northern and Southern hemispheres vary almost simultaneously in the entire substorm interval 16-19 UT, values of the fluxes in two hemispheres coinciding up to $\sim 5 \%$.

2. For observed $B_{y}>0$, the expected asymmetry is between magnetic fluxes in the dawn and dusk parts of the polar caps in two hemispheres: $\Psi_{\mathrm{N} \text {, dawn }}>\Psi_{\mathrm{N} \text {, dusk }}$ in the Northern Hemisphere and, conversely, $\Psi_{\mathrm{S} \text {, dawn }}<\Psi_{\mathrm{S} \text {, dusk }}$ in the Southern Hemisphere.

3. The asymmetry, described in Section 2, decreases in both hemispheres with the development of each of the two substorms that began at 16:20 and 18:40 UT.

It should be emphasized once again that all the results for two hemispheres have been obtained using the extended ground MIT. The observed dawn-dusk asymmetry in PC configurations of two hemispheres (the main result 2 is visually confirmed by simultaneous optical observations of auroral ovals in the $\mathrm{N}$ and $\mathrm{S}$ hemispheres from IMAGE and Polar satellites [Østgaard et al., 2018]. Figure 5 presents satellite images of distributions of auroras in the $\mathrm{N}$ and $\mathrm{S}$ hemispheres for four moments selected from the substorm interval 1619 UT. The corresponding PC R0 boundaries found by MIT are superimposed on the auroral images: in the $\mathrm{N}$ hemisphere, the PC R0 boundary (closed blue line); in the $\mathrm{S}$ hemisphere, the PC R0 boundary (closed red line). Not in all MLT sectors but in general there is quite a close correspondence between the PC R0 boundaries and northern boundaries of auroral brightness. Main result 2 is obvious from the PC R0 shift to dawn in the $\mathrm{N}$ hemisphere and to dusk in the $\mathrm{S}$ hemisphere. Under close examination of the satellite images, the same dawndusk asymmetry can be seen in distributions of auroras; this asymmetry has been studied in detail by Østgaard et al. [2018].

Since we discuss all the results in the text in respective sections, let us go on to Conclusion.

\section{CONCLUSION}

Let us list the main results and conclusions obtained in this paper.

1. We have first tested the extended MIT in the uniform ionospheric conductance approximation and using the SuperMAG database. For the selected interval of the August 17, 2001 magnetic storm with one-minute step, we calculated 2D distributions of the equivalent current function (electric potential) and FACs in the Northern and Southern hemispheres. The comparative analysis of 200 maps of these distributions confirms the expected interhemispheric similarity between large-scale systems of ionospheric convection and FACs, and hence good prospects for the development of MIT for the polar ionosphere of the Southern Hemisphere.

2. The analysis of the dynamics of the convection and FAC systems in two hemispheres during the August
17, 2001 magnetic storm yielded the expected and interpretable results.

2.1. Variations in Hall current intensities in polar caps and auroral electrojets occur fairly concurrently in both hemispheres, and the electrojets in the $\mathrm{N}$ hemisphere are markedly more intense than those in the $S$ hemisphere, and the Hall current in the north polar cap is approximately twice as strong as in the south one; this interhemispheric asymmetry is presumably due to seasonal variation in the ionospheric conductance, which is implicitly contained in the equivalent current function.

2.2. Magnetic fluxes through the polar caps of the $\mathrm{N}$ and $\mathrm{S}$ hemispheres match up to $\sim 5 \%$ and vary almost simultaneously in the entire substorm interval 16-19 UT of the magnetic storm.

2.3. The detected asymmetries of magnetic fluxes through the dawn and dusk parts of polar caps in two hemispheres: $\Psi_{\mathrm{N} \text {, dawn }}>\Psi_{\mathrm{N} \text {, dusk }}$ in the $\mathrm{N}$ hemisphere and, conversely, $\Psi_{\mathrm{S} \text {, dawn }}<\Psi_{\mathrm{S} \text {, dusk }}$ in the $\mathrm{S}$ hemisphere concur with the theory for $B_{y}>0$ and with satellite images of auroral ovals; both the asymmetries decrease during the magnetic storm and substorm.

We have obtained the first, fundamentally important result in the approximation of uniform ionospheric conductances in both hemispheres. The next stage of the work in the chosen area of research is aimed at calculating the electric potential, horizontal and field-aligned currents in two ionospheres with non-uniform conductances. We will utilize a substantially updated dynamic model of ionospheric conductance, produced by precipitating electrons and ions, which is analogous to previous models [Mishin et al., 1986; Shirapov et al., 2000; Lunyushkin, Penskikh, 2019].

The work was performed with budgetary funding of Basic Research program II.16 and with partial support from RFBR grant No. 18-05-00437. Experimental data were obtained using the equipment of Center for Common Use "Angara" http://ckp-rf.ru/ckp/3056. We thank Mishin V.M. and Tashchilin A.V. for their interest in this work and useful discussions.

For the ground magnetometer data we gratefully acknowledge the following: Intermagnet; USGS, Jeffrey J. Love; CARISMA, PI Ian Mann; CANMOS; The SRAMP Database, PI K. Yumoto and Dr. K. Shiokawa; The SPIDR database; AARI, PI Oleg Troshichev; The MACCS program, PI M. Engebretson, Geomagnetism Unit of the Geological Survey of Canada; GIMA; MEASURE, UCLA IGPP and Florida Institute of Technology; SAMBA, PI Eftyhia Zesta; 210 Chain, PI K. Yumoto; SAMNET, PI Farideh Honary; The institutes who maintain the IMAGE magnetometer array, PI Eija Tanskanen; PENGUIN; AUTUMN, PI Martin Connors; DTU Space, PI Dr. Rico Behlke; South Pole and McMurdo Magnetometer, PI's Louis J. Lanzarotti and Alan T. Weatherwax; ICESTAR; RAPIDMAG; PENGUIn; British Artarctic Survey; McMac, PI Dr. Peter Chi; BGS, PI Dr. Susan Macmillan; Pushkov Institute of Terrestrial Magnetism, Ionosphere and Radio Wave Propagation (IZMIRAN); GFZ, PI Dr. Juergen Matzka; MFGI, PI B. Heilig; IGFPAS, PI J. Reda; University of 
SI13, North

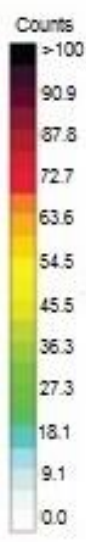

$18: 11: 33$

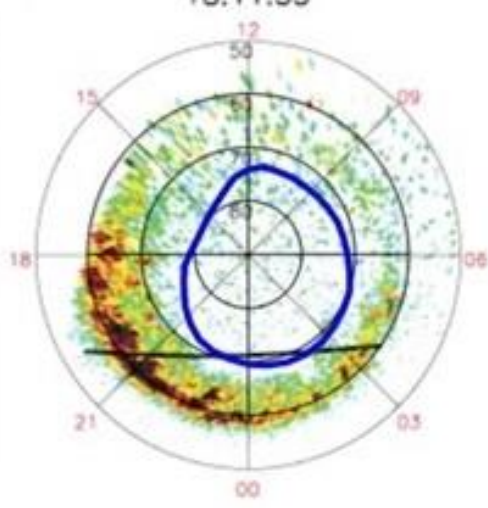

18:13:35

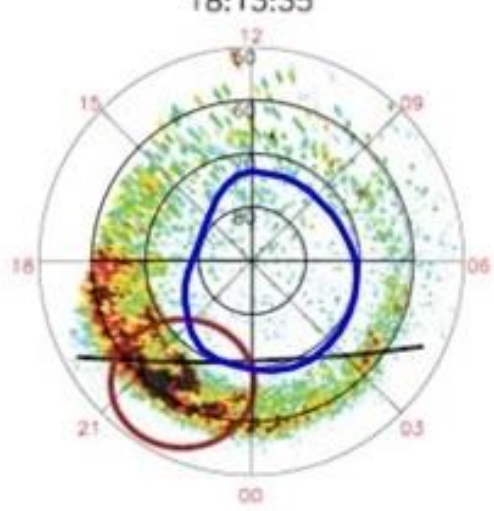

$18: 17: 41$

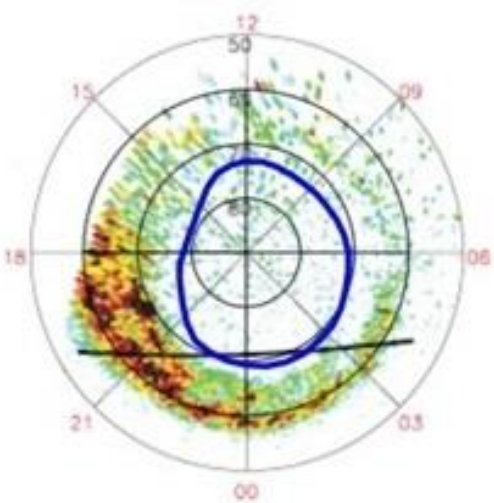

$18: 54: 29$

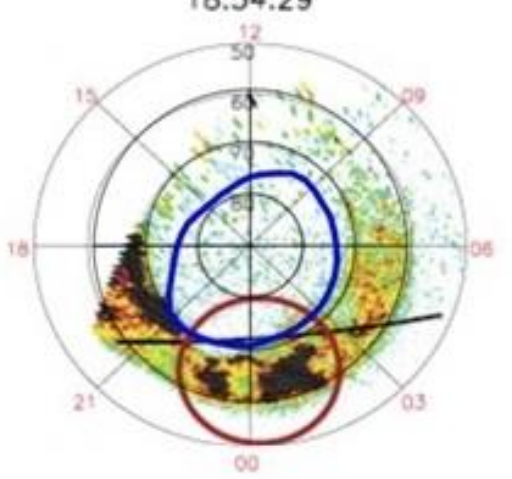

VIS, South

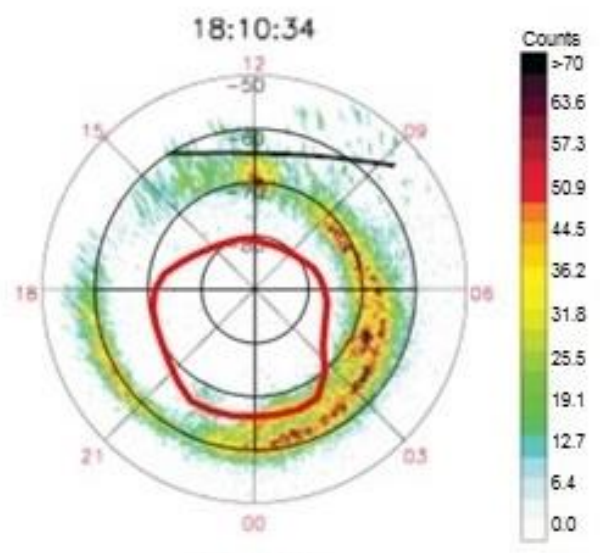

18:13:16

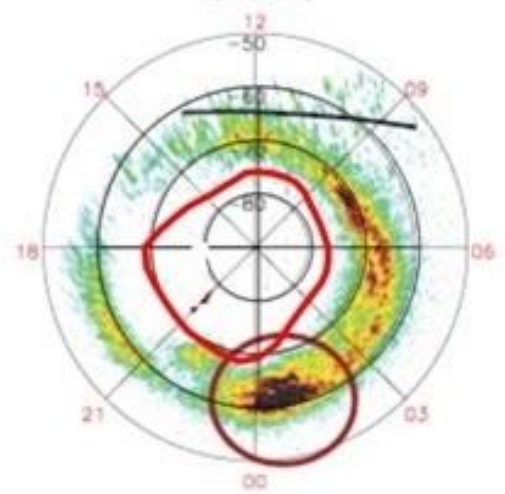

$18: 17: 46$

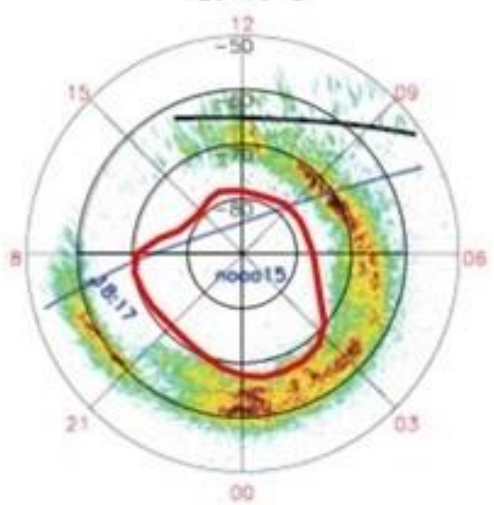

$18: 53: 51$

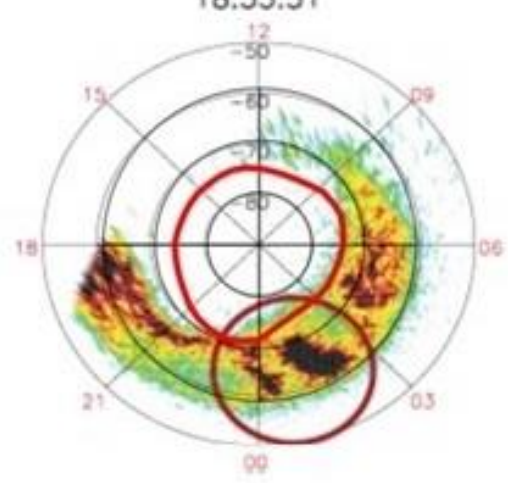

Figure 5. A copy of Figure 4 from [Østgaard et al., 2018]. Images of auroras in the $\mathrm{N}$ hemisphere obtained from the IMAGE satellite for selected moments of the substorm interval 16-19 UT of the August 17, 2001 magnetic storm (left). Simultaneous images of auroras in the $\mathrm{S}$ hemisphere from the Polar satellite; the terminator is indicated by the thick black line; brown circles show areas of adjacent aurora features in two hemispheres (right). The polar cap boundaries R0, obtained using MIT for respective moments in the Northern (closed blue line) and Southern (closed red line) hemispheres, are superimposed on the images of auroras 
L'Aquila, PI M. Vellante; BCMT, V. Lesur and A. Chambodut; Data obtained in cooperation with Geoscience Australia, PI Marina Costelloe; SuperMAG, PI Jesper W. Gjerloev. Data used in this study are available on the SuperMAG website [http://supermag.jhuapl.edu].

\section{REFERENCES}

Akasofu S.I. Physics of Magnetospheric Substorms. Dordrecht, Holland, Springer Netherlands, 1977, 617 p. DOI: 10.1007/978-94-010-1164-8_1.

Axford W.I. Viscous interaction between the solar wind and the Earth's magnetosphere. Planet. Space Sci. 1964, vol. 12, no. 1, pp. 45-53. DOI: 10.1016/0032-0633(64)90067-4.

Axford W.I., Hines C.O. A unifying theory of high-latitude geophysical phenomena and geomagnetic storms. Can. J. Phys. 1961, vol. 39, no. 10, pp. 1433-1464. DOI: 10.1139/p61-172.

Bazarzhapov A.D., Matveev M.I., Mishin V.M. Geomagnitnye variatsii $i$ buri [Geomagnetic Variations and Storms]. Novosibirsk, U.S.S.R., Nauka Publ. 1979, 248 p. (In Russian).

Boström R. Ionosphere-magnetosphere coupling. Magnetospheric Physics. Ed. by B.M. McCormac, D. Reidel. Publishing Company, Dordrecht-Holland, 1974, pp. 45-59.

Cattell C., Dombeck J., Preiwisch A., Thaller S., Vo P., Wilson III L.B., et al. Observations of a high-latitude stable electron auroral emission at $\sim 16$ MLT during a large substorm. J. Geophys. Res. 2011, vol. 116, no. A7, A07215. DOI: 10.1029/2010ja016132.

Chapman S., Bartels J. Geomagnetism. Vol. 1-2. Great Britain, Oxford University Press, 1940, 1125 p.

Coley W.R. Spatial relationship of field-aligned currents, electron precipitation, and plasma convection in the auroral oval. J. Geophys. Res. 1983, vol. 88, no. A9, pp. 7131-7141. DOI: 10.1029/JA088iA09p07131.

Cowley S.W.H. Magnetospheric asymmetries associated with the $y$-component of the IMF. Planet. Space Sci. 1981, vol. 29, no. 1, pp. 79-96. DOI: 10.1016/0032-0633(81)90141-0.

Cowley S.W.H., Lockwood M. Excitation and decay of solar-wind driven flows in the magnetosphere-ionosphere system. Ann. Geophys. 1992, vol. 10, pp. 103-115.

Coxon J.C., Milan S.E., Anderson B.J. A Review of Birkeland Current Research Using AMPERE. Electric Currents in Geospace and Beyond. Ed. by A. Keiling et al. Hoboken, New Jersey, USA, Wiley-AGU, Geophysical Monograph Ser., 2018, vol. 235, pp. 259-278. DOI: 10.1002/9781119324522.ch16.

Deng Y., Lu G., Kwak Y.-S., Sutton E., Forbes J., Solomon S. Reversed ionospheric convections during the November 2004 storm: Impact on the upper atmosphere. J. Geophys. Res. 2009, vol. 114, no. A7, A07313. DOI: 10.1029/2008ja013793.

Dungey J.W. Interplanetary magnetic field and the auroral zones. Phys. Rev. Lett. 1961, vol. 6, no. 2, pp. 47-48. DOI: 10.1103/PhysRevLett.6.47.

Fukushima N. Electric current systems for polar substorms and their magnetic effect below and above the ionosphere. Radio Sci. 1971, vol. 6, no. 2, pp. 269-275. DOI: $10.1029 / \mathrm{RS} 006 \mathrm{i002p00269.}$

Fukushima N. Generalized theorem for no ground magnetic effect of vertical currents connected with Pedersen currents in the uniform-conductivity ionosphere. Report of Ionosphere and Space Research in Japan. 1976, vol. 30, no. 1-2, pp. 35-40.

Gjerloev J.W. The SuperMAG data processing technique. $J$. Geophys. Res. 2012, vol. 117, no. A9, A09213. DOI: 10.1029/ $2012 \mathrm{ja} 017683$.

Haaland S., Runov A., Forsyth C. (Eds.). Dawn-Dusk Asymmetries in Planetary Plasma Environments. Hoboken, New Jersey, USA, Wiley-AGU, 2017, 361 p. (Geophysical Monograph Ser., vol. 230).
Heelis R.A. Advances in Understanding Ionospheric Convection at High Latitudes. Magnetosphere-Ionosphere Coupling in the Solar System. John Wiley \& Sons, Inc., 2016, pp. 49-59. DOI: 10.1002/9781119066880.ch4.

Heikkila W.J. Earth's Magnetosphere: Formed by the Low-Latitude Boundary Layer. Amsterdam, Elsevier Science, 2011, 536 p. DOI: 10.1016/B978-0-444-52864-3.10012-7.

Iijima T., Potemra T.A. Large-scale characteristics of fieldaligned currents associated with substorms. J. Geophys. Res. 1978, vol. 83, no. A2, pp. 599-615. DOI: 10.1029/JA083iA02p 00599.

Kamide Y., Matsushita S. Simulation studies of ionospheric electric fields and currents in relation to field-aligned currents. 1. Quiet periods. J. Geophys. Res. 1979, vol. 84, no. A8, pp. 4083-4098. DOI: 10.1029/JA084iA08p04083.

Kamide Y., Richmond A.D. Ionospheric conductivity dependence of electric fields and currents estimated from ground magnetic observations. J. Geophys. Res. 1982, vol. 87, no. A10, pp. 8331-8337. DOI: 10.1029/JA087iA10p08331.

Kamide Y., Baumjohann W. Magnetosphere-ionosphere coupling. Berlin, Springer Berlin Heidelberg, 1993, 178 p. DOI: 10.1007/978-3-642-50062-6.

Karavaev Y.A., Mishin V.M., Pu Z. Events of 17 August 2001. I. Development of the loading-unloading phase during the storm. Solar-Terr. Phys. 2011, no. 19, pp. 55-61. (In Russian).

Karavaev Y.A., Mishin V.M., Lunyushkin S.B., Sukhbaatar U., Moiseev A.V., Shirapov D.S. Comparison of the boundaries and areas of the polar cap, determined on the basis of magnetogram inversion technique, images of auroras and MHD modeling. Physics of Auroral Phenomena: Proc. XXXVI Annual Seminar, Apatity. Ed. by A.G. Yahnin. Kola Science Centre, Russian Academy of Science, 2013, pp. 29-32. (In Russian).

Kern J.W. Analysis of polar magnetic storms. J. Geomag. Geoelectr. 1966, vol. 18, no. 2, pp. 125-131. DOI: $10.5636 /$ jgg.18.125.

Kondratyev A.B., Penskikh Y.V., Lunyushkin S.B. Automated method for determining auroral oval boundaries, based on the magnetogram inversion technique. Baikal Young Scientists' International School on Fundamental Physics: Proc. of XV Conference of Young Scientists "The Interaction of Fields and Radiation with Matter". Irkutsk, 11-16 September 2017. Ed. by I.P. Yakovleva. Irkutsk, ISTP SB RAS, 2017, pp. 107-112. (In Russian).

Koskinen H.E.J. Physics of Space Storms: From the Solar Surface to the Earth. Dordrecht, Holland, Springer Berlin Heidelberg, 2011, 419 p. DOI: 10.1007/978-3-642-00319-6.

Laundal K.M., Haaland S.E., Lehtinen N., Gjerloev J.W., Østgaard N., Tenfjord P., et al. Birkeland current effects on high-latitude ground magnetic field perturbations. Geophys. Res. Lett. 2015, vol. 42, no. 18, pp. 7248-7254. DOI: $10.1002 / 2015 \mathrm{gl} 1065776$.

Lee L.C., Roederer J.G. Solar wind energy transfer through the magnetopause of an open magnetosphere. J. Geophys. Res. 1982, vol. 87, no. A3, pp. 1439-1444. DOI: 10.1029/JA087i A03p01439.

Leonovich A.S., Mishin V.V., Cao J.B. Penetration of magnetosonic waves into the magnetosphere: influence of a transition layer. Ann. Geophys. 2003, vol. 21, no. 5, pp. 10831093. DOI: 10.5194/angeo-21-1083-2003.

Leontyev S.V., Lyatsky W.B. Electric field and currents connected with $y$-component of interplanetary magnetic field. Planet. Space Sci. 1974, vol. 22, no. 5, pp. 811-819. DOI: 10.1016/0032-0633(74)90151-2.

Levitin A.E., Afonina R.G., Belov B.A., Feldstein Y.I. Geomagnetic variation and field-aligned currents at northern high-latitudes, and their relations to the solar wind parameters. Phil. Trans. R. Soc. Lond. A. 1982, vol. 304, no. 1484, pp. 253301. DOI: $10.1098 /$ rsta.1982.0013. 
Longley W., Reiff P., Daou A.G., Hairston M. Conjugate aurora location during a strong IMF by storm. Dawn-Dusk Asymmetries in Planetary Plasma Environments. John Wiley \& Sons Inc., 2017, pp. 285-294. DOI: 10.1002/9781119216346.ch22.

$\mathrm{Lu}$ G., Richmond AD, Emery BA, Reiff PH, de la Beaujardière O., Rich F. J., et al. Interhemispheric asymmetry of the high-latitude ionospheric convection pattern. J. Geophys. Res. 1994, vol. 99, no. A4, pp. 6491-6510. DOI: 10.1029/93ja03441.

Lu G., Li W.H., Raeder J., Deng Y., Rich F., Ober D., et al. Reversed two-cell convection in the Northern and Southern hemispheres during northward interplanetary magnetic field. J. Geophys. Res. 2011, vol. 116, no. A12, A12237. DOI: $10.1029 / 2011$ ja017043.

Lunyushkin S.B., Penskikh Y.V. Diagnostics of the auroral oval boundaries on the basis of the magnetogram inversion technique. Solar-Terr. Phys. 2019, vol. 5, no. 2, pp. 97-113. DOI: $10.12737 /$ szf-51201907.

Matveev M.I., Shpynev G.B. Determination of electric fields and field-aligned currents in the magnetosphere on data of geomagnetic variations (high-latitude region). Issledovaniya po geomagnetizmu, aeronomii i fizike Solntsa. [Research on Geomagnetism, Aeronomy and Solar Physics]. 1975, iss. 36, pp. 34-39. (In Russian).

Milan S.E., Evans T.A., Hubert B. Average auroral configuration parameterized by geomagnetic activity and solar wind conditions. Ann. Geophys. 2010, vol. 28, no. 4, pp. 1003 1012. DOI: $10.5194 /$ angeo-28-1003-2010.

Milan S.E., Clausen L.B.N., Coxon J.C., Carter J.A., Walach M.-T., Laundal K., Østgaard N., Tenfjord P., Reistad J., Snekvik K., Korth H., Anderson B.J. Overview of solar wind magnetosphere - ionosphere - atmosphere coupling and the generation of magnetospheric currents. Space Sci. Rev. 2017, vol. 206, no. 1, pp. 547-573. DOI: 10.1007/s11214-0170333-0.

Mishin V.M. The magnetogram inversion technique and some applications. Space Sci Rev. 1990, vol. 53, no. 1-2, pp. 83-163. DOI: 10.1007/bf00217429.

Mishin V.V. Velocity boundary layers in the distant geotail and the Kelvin-Helmholtz instability. Planet. Space Sci. 2005 , vol. 53, no. 1-3, pp. 157-160. DOI: 10.1016/j.pss.2004.09.040.

Mishin V.M., Bazarzhapov A.D. Selection of the spectrum of Legendre polynomials approximating the observed Sq-field. Geomagnetic Res. 1966, no. 8, pp. 23-30. (In Russian).

Mishin V.M., Popov G.V. On field-aligned currents in the magnetosphere. Issledovaniya po geomagnetizmu, aeronomii fizike Solntsa. [Research on Geomagnetism, Aeronomy and Solar Physics]. 1969, iss. 8, pp. 3-28. (In Russian).

Mishin V.M., Shpynev G.B., Bazarshapov A.D., Shirapov D.S. Electric field and currents in the nonuniformly-conductive high-latitude ionosphere. Issledovaniya po geomagnetizmu, aeronomii $i$ fizike Solntsa. [Research on Geomagnetism, Aeronomy and Solar Physics]. 1981, iss. 53, pp. 116-133. (In Russian).

Mishin V.M., Saifudinova T.I., Shirapov D.S., Lunyushkin S.B., Shelomentzev V.V. The analysis of CDAW-6 substorms of 22 March 1979. Issledovaniya po geomagnetizmu, aeronomii i fizike Solntsa. [Research on Geomagnetism, Aeronomy and Solar Physics]. 1984, iss. 68, pp. 151-201. (In Russian).

Mishin V.M., Lunyushkin S.B., Shirapov D.S., Baumjohann W. A new method for generating instantaneous ionospheric conductivity models using ground-based magnetic data. Planet. Space Sci. 1986, vol. 34, no. 8, pp. 713-722. DOI: 10.1016/0032-0633(86)90125-x.

Mishin V.M., Bazarzhapov A.D., Saifudinova T.I., Lunyushkin S.B., Shirapov D.S., Woch J., et al. Different methods to determine the polar cap area. J. Geomag. Geoelectr. 1992, vol. 44, no. 12, pp. 1207-1214. DOI: 10.5636/jgg.44.1207.

Mishin V.M., Block L.P., Bazarzhapov A.D., Saifudinova T.I., Lunvushkin S.B., Shirapo D.Sh., et al. A study of the CDAW 9C substorm of May 3, 1986, using magnetograrn inversion technique 2, and a substorm scenario with two active phases. J. Geophys. Res. 1997, vol. 102, no. A9, pp. 19845-19859. DOI: $10.1029 / 97 \mathrm{ja} 00154$.

Mishin V.V., Mishin V.M., Pu Z., Lunyushkin S.B., Sapronova L.A., Sukhbaatar U., Baishev D.G. Old tail lobes effect on the solar wind - magnetosphere energy transport for the 27 August 2001 substorm. Adv. Space Res. 2014, vol. 54, no. 12, pp. 2540-2548. DOI: 10.1016/j.asr.2014.09.013.

Østgaard N., Reistad J.P., Tenfjord P., Laundal K.M., Rexer T., Haaland S.E., et al. The asymmetric geospace as displayed during the geomagnetic storm on August 17, 2001. Ann. Geophys. Discuss. 2018, vol. 2018, pp. 1-31. DOI: 10.5194/angeo-2018-65.

Papitashvili V.O., Rich F.J. High-latitude ionospheric convection models derived from Defense Meteorological Satellite Program ion drift observations and parameterized by the interplanetary magnetic field strength and direction. J. Geophys. Res. 2002, vol. 107, no. A8, p. 1198. DOI: 10.1029/2001ja 000264.

Papitashvili V.O., Belov B.A., Faermark D.S., Feldstein Y.I., Golyshev S.A., Gromova L.I., Levitin A.E. Electric potential patterns in the northern and southern polar regions parameterized by the interplanetary magnetic field. J. Geophys. Res. 1994, vol. 99, no. A7, pp. 1325113262. DOI: $10.1029 / 94$ ja00822.

Pettigrew E.D., Shepherd S.G., Ruohoniemi J.M. Climatological patterns of high-latitude convection in the Northern and Southern hemispheres: Dipole tilt dependencies and interhemispheric comparisons. J. Geophys. Res. 2010, vol. 115, no. A7, A07305. DOI: 10.1029/2009JA014956.

Reiff P.H. Models of auroral-zone conductances. Magnetospheric Currents. Ed. by T.A. Potemra. Washington, DC, AGU, 1984, pp. 180-191. DOI: 10.1029/GM028p0180.

Richmond A.D., Kamide Y. Mapping electrodynamic features of the high-latitude ionosphere from localized observations: Technique. J. Geophys. Res. 1988, vol. 93, no. A6, pp. 5741-5759. DOI: 10.1029/JA093iA06p05741.

Ridley A.J., Lu G., Clauer C.R., Papitashvili V.O. A statistical study of the ionospheric convection response to changing interplanetary magnetic field conditions using the assimilative mapping of ionospheric electrodynamics technique. J. Geophys. Res. 1998, vol. 103, no. A3, pp. 4023-4039. DOI: 10.1029/ 97ja03328.

Shirapov D.S., Mishin V.M., Bazarzhapov A.D., Saifudinova T.I. Adapted dynamic model of ionospheric conductivity. Geomagnetism and Aeronomy. 2000, vol. 40, no. 4, pp. 471-475.

Sun W., Lee L.C., Kamide Y., Akasofu S.I. An improvement of the Kamide-Richmond-Matsushita scheme for the estimation of the three-dimensional current system. J. Geophys. Res. 1985, vol. 90, no. A7, pp. 64696474. DOI: 10.1029/JA090iA07p06469.

Tenfjord P., Østgaard N., Snekvik K., Laundal K.M., Reistad J.P., Haaland S., Milan S.E. How the IMF $B_{y}$ induces a $B_{y}$ component in the closed magnetosphere and how it leads to asymmetric currents and convection patterns in the two hemispheres. J. Geophys. Res:. Space Phys. 2015, vol. 120, no. 11, pp. 9368-9384. DOI: 10.1002/2015ja021579.

Tenfjord P., Østgaard N., Strangeway R., Haaland S., Snekvik K., Laundal K.M., Reistad J.P., Milan S.E. Magnetospheric response and reconfiguration times following IMF $B_{y}$ reversals. J. Geophys. Res.: Space Phys. 2017, vol. 122, no. 1 , pp. 417-431. DOI: 10.1002/2016ja023018.

Weimer D.R. Maps of ionospheric field-aligned currents as a function of the interplanetary magnetic field derived from Dynamics Explorer 2 data. J. Geophys. Res. 2001, vol. 106, no. A7, pp. 12889-12902. DOI: 10.1029/2000ja000295.

Weimer D.R. Improved ionospheric electrodynamic models and application to calculating Joule heating rates. J. Geophys. Res. 
2005, vol. 110, no. A5, A05306. DOI: 10.1029/2004ja010884.

URL: https://omniweb.gsfc.nasa.gov (accessed December 22, 2018).

URL: http://wdc.kugi.kyoto-u.ac.jp/index.html (accessed December 22, 2018)

URL: http://supermag.jhuapl.edu (accessed December 22, 2018).

How to cite this article.

Lunyushkin S.B., Mishin V.V., Karavaev Yu.A., Penskikh Yu.V., Kapustin V.E. Studying the dynamics of electric currents and polar caps in ionospheres of two hemispheres during the August 17, 2001 geomagnetic storm. Solar-Terrestrial Physics. 2019. Vol. 5. Iss. 2. P. 15-27. DOI: $10.12737 /$ stp-52201903. 